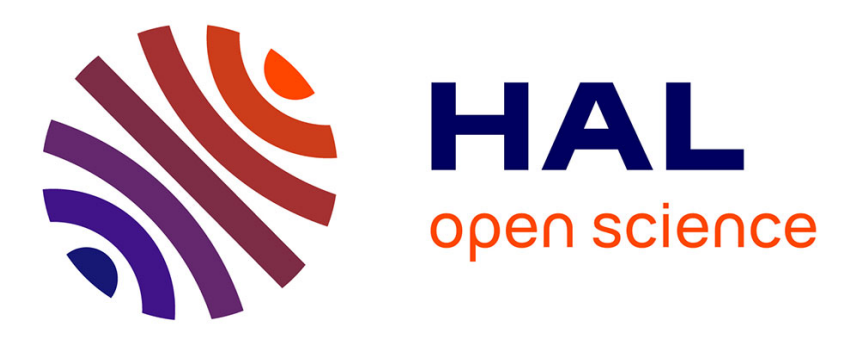

\title{
Thermoresponsive properties of poly(acrylamide-co-acrylonitrile)-based diblock copolymers synthesized (by PISA) in water
}

Nicolas Audureau, Fanny Coumes, Jean-Michel Guigner, Thi Phuong Thu Nguyen, Christine Ménager, François Stoffelbach, Jutta Rieger

\section{To cite this version:}

Nicolas Audureau, Fanny Coumes, Jean-Michel Guigner, Thi Phuong Thu Nguyen, Christine Ménager, et al.. Thermoresponsive properties of poly(acrylamide-co-acrylonitrile)-based diblock copolymers synthesized (by PISA) in water. Polymer Chemistry, In press, 10.1039/D0PY00895H . hal-02943202

\section{HAL Id: hal-02943202 \\ https: / hal.sorbonne-universite.fr/hal-02943202}

Submitted on 18 Sep 2020

HAL is a multi-disciplinary open access archive for the deposit and dissemination of scientific research documents, whether they are published or not. The documents may come from teaching and research institutions in France or abroad, or from public or private research centers.
L'archive ouverte pluridisciplinaire HAL, est destinée au dépôt et à la diffusion de documents scientifiques de niveau recherche, publiés ou non, émanant des établissements d'enseignement et de recherche français ou étrangers, des laboratoires publics ou privés. 


\section{Thermoresponsive properties of poly(acrylamide-co-acrylonitrile)-based}

\section{diblock copolymers synthesized (by PISA) in water"}

Nicolas Audureau ${ }^{1}$, Fanny Coumes ${ }^{1}$, Jean-Michel Guigner ${ }^{2}$, Thi Phuong Thu Nguyen ${ }^{1}$, Christine Ménager $^{3}$, François Stoffelbach ${ }^{1 *}$, Jutta Rieger $^{1 *}$

${ }^{1}$ Sorbonne Université, CNRS, UMR 8232, Institut Parisien de Chimie Moléculaire (IPCM), Polymer Chemistry Team, 4 Place Jussieu, 75252 Paris Cedex 05, France

${ }^{2}$ Sorbonne Université, CNRS, UMR 7590 Institut de Minéralogie, de Physique des Matériaux et de Cosmochimie (IMPMC)-IRD-MNHN, F-75005 Paris, France

${ }^{3}$ Sorbonne Université, CNRS, UMR 8234, PHENIX Laboratory, 4 place Jussieu, 75252 Paris cedex 05, France

E-mail: jutta.rieger@ sorbonne-universite.fr francois.stoffelbach@ sorbonne-universite.fr

\#This manuscript is in honor of the 50-year anniversary of the French Polymer Group (Groupe Français des Polymères - GFP)

\section{FIGURE FOR TOC}

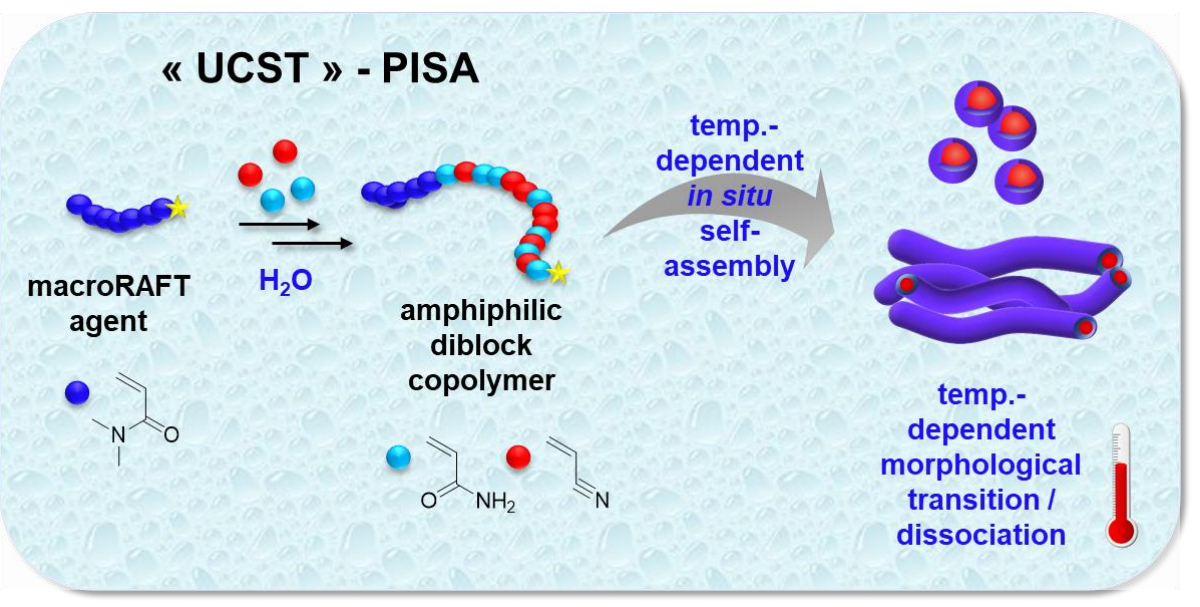




\title{
Text for TOC
}

UCST-type poly(acrylamide-co-acrylonitrile) diblock copolymers synthesized in water (by PISA) can not only undergo reversible temperature-induced chain dissociation, but also temperatureinduced morphological transition.

\begin{abstract}
In this present work, we report the synthesis of UCST-thermoresponsive diblock copolymers using reversible addition fragmentation chain transfer (RAFT) polymerization in aqueous media. A water-soluble poly( $N, N$-dimethylacrylamide) macromolecular chain transfer agent (PDMAc macroRAFT) is used to promote and control the copolymerization of acrylamide and acrylonitrile in water and obtain PDMAc- $b$-P(AAm-co-AN) diblock copolymers. The $\mathrm{f}_{\mathrm{AN}, 0}$ and the length of the thermosensitive block $\left(D P_{\mathrm{n}}\right)$ are systematically varied, in order to study their influence on the thermoresponsiveness of the block copolymers. A good blocking efficiency is generally evidenced by size exclusion chromatography. Remarkably, amphiphilic copolymers nanoparticles are formed in situ for the highest $\mathrm{f}_{\mathrm{AN}, 0}$. This is indeed the first time that such particles are produced by a polymerization-induced self-assembly (PISA) process. The morphology of the in-situ formed nanoparticles and their behavior with temperature are studied by means of dynamic light scattering (DLS), (cryogenic) transmission electron microscopy ((cryo)-TEM) and turbidimetry. Spherical and worm-like nanoparticles are formed which exhibit unexpected properties, such as an unprecedented temperature-induced worm-to-sphere morphological transition.
\end{abstract}




\section{Introduction}

Stimuli-responsive polymers and in particular thermosensitive polymers, presenting an upper or a lower critical solution temperature, namely UCST and LCST respectively, have been widely investigated during the past decade for various applications, such as tissue engineering, drug delivery or thermal sensing. ${ }^{1-6}$ LCST polymers present a coil-to-globule conformation transition upon temperature increase and have been extensively studied in the literature. ${ }^{7-9}$ In contrast, UCST polymers, which present the opposite conformational transition and are insoluble below and soluble above a critical temperature, have been less studied. Since recently, researchers try to understand and exploit UCST polymers at the same extent as LCST polymers, with a particular interest in UCST-type polymers which undergo this transition in water. ${ }^{10-13}$ Indeed such polymers attract a great interest due to their great range of applicability, especially in the biomedical field. ${ }^{14}$ Polymers that exhibit a UCST-type transition in water can be divided in two main classes. The first one includes ionic UCST polymers, where the transition relies on the modification of electrostatic interactions. Within this family, zwitterionic polymers such as some polysulfobetaines (PSB) ${ }^{15-19}$ or polycarboxybetaines $(\mathrm{PCB})^{20}$, present interesting UCST properties since their thermosensitivity depends on the aqueous environment such as the presence of electrolytes or adjustment of the solution $\mathrm{pH} \cdot{ }^{21}$ Nevertheless, such sensitivity to subtle changes in the aqueous medium is not always desired. The second class of UCST polymers, where the transition relies mainly on hydrogen bonds, is non-ionic UCST polymers. They are generally less sensitive to the aforementioned 
changes. The most studied neutral UCST polymers are $N$-acryloylglycinamide (NAGA) (co)polymers ${ }^{22-29}$, polymers possessing ureido-moities ${ }^{30-33}$ and (co)polymers based on (meth)acrylamide ((M)AAm) $)^{34-39}$. Among the latter family, the statistical copolymer poly(acrylamide-co-acrylonitrile) (P(AAm-co-AN)) has gained more and more interest. ${ }^{3}$ Indeed, the latter was largely used to engineer thermoresponsive/stimuli-responsive block copolymer systems for drug delivery purposes, cancer theranostics/chemotherapy and photoacoustic imaging. ${ }^{40-52}$ It is generally obtained by radical copolymerization of acrylamide and acrylonitrile in organic solvents, mainly in dimethylsulfoxide (DMSO). Both free radical polymerization (FRP) and reversible deactivation radical polymerization (RDRP) $)^{53-58}$ mechanisms - in particular the reversible addition fragmentation chain transfer (RAFT) - have been used. For instance, Agarwal et al. evidenced in 2012 that such copolymer synthesized in DMSO by FRP, exhibited a thermoresponsive character between 6 and $60{ }^{\circ} \mathrm{C}$, tunable by the acrylonitrile content in the copolymer, with a sharp transition and a small hysteresis which did not change upon salinity or $\mathrm{pH}$ modification. ${ }^{53}$ In 2019, Uchiyama et al. outlined the importance of the polymerization procedure - RDRP versus FRP, in DMSO - over the thermoresponsive properties. ${ }^{58}$ They evidenced that the AAm/AN composition within the polymer chains changed greatly depending on the polymerization technique used and had a great impact on the transition temperature. In contrast, the molar mass had little to no effect on the transition temperature. The authors highlighted in particular the interest of such biocompatible copolymers for pharmaceutical and cosmetic applications. In these former studies, the P(AAm-co-AN) copolymers were synthesized in organic solvent. While a few reports can be found in the literature studying the copolymerization of acrylamide and acrylonitrile in water using FRP ${ }^{59,60}$, it was only very recently that Ferji et al. ${ }^{61}$ reported the first example of such a copolymerization in water using the photo-RAFT technique. Statistical copolymers with initial acrylonitrile content $\left(\mathrm{f}_{\mathrm{AN}, 0}\right)$ ranging from 0 to 0.5 were formed with good polymerization control, 
and again it was shown that the thermoresponsive properties depended on the copolymer composition. Furthermore, the comparison of two copolymers differing in their number-average degree of polymerization $\left(D P_{\mathrm{n}} \sim 500\right.$ and 1000, for similar AN content) did not reveal any significant influence of the molar mass on the transition temperature. ${ }^{61}$

In this study, we used a water-soluble poly $(N, N$-dimethylacrylamide $)$ macromolecular chain transfer agent (PDMAc macroRAFT) to promote and control the radical copolymerization of acrylamide and acrylonitrile and synthesize, for the first time in water, such diblock copolymers with a thermosensitive $\mathrm{P}(\mathrm{AAm}-\mathrm{co}-\mathrm{AN})$ block. The initial acrylonitrile content $\left(\mathrm{f}_{\mathrm{AN}, 0}\right)$ and the length of the thermosensitive block $\left(D P_{\mathrm{n}}\right)$ were varied, in order to study their influence on the thermoresponsiveness of the block copolymers. In addition, a series of polymerizations was also performed with high $\mathrm{AN}$ content $\left(\mathrm{f}_{\mathrm{AN}, 0}>0.5\right)$ in dispersion polymerization conditions. In this case, amphiphilic copolymers nanoparticles formed in situ during chain extension through a polymerization-induced self-assembly (PISA) process. Spherical and worm-like nanoparticles were obtained, and their thermoresponsive behavior investigated by (cryo-)TEM, turbidimetry and dynamic light scattering (DLS) experiments. For specific compositions, an unexpected temperature-induced morphological transition was observed.

\section{Experimental part}

\subsection{Materials}

2,2'-Azobis[2-(2-imidazolin-2-yl)propane]dihydrochloride (VA-044) (Aldrich, 98\%), azobisisobutyronitrile (AIBN) (Aldrich, $\geq 98 \%$ ), 1,3,5-trioxane (Aldrich, $\geq 99 \%$ ), acrylamide (AAm) (Aldrich, $\geq 99 \%$ ) and $N, N$-dimethylformamide (DMF) (VWR, Normapur), polyacrylamide 
(PAAm) (Polysciences) were used as received without further purification. Acrylonitrile (AN) (Prolabo, 99\%) and N,N-dimethylacrylamide (DMAc) (Aldrich, $\geq 99 \%$ ) were distilled under reduced pressure before use. The RAFT agent (HOOC-TTC) was synthesized according to a protocol previously described in the literature. ${ }^{62}$ Deionized water was used for all copolymerizations of AAm with AN.

\subsection{Synthesis}

\section{Synthesis of the poly( $N, N$-dimethylacrylamide) macroRAFT agents, PDMAc-TTC}

In a typical experiment (Table S1, entry M2), $182 \mathrm{mg}(0.72 \mathrm{mmol})$ of RAFT agent (HOOC-TTC) (see Scheme 1), $70 \mathrm{mg}(0.78 \mathrm{mmol})$ of trioxane (added as an internal reference for the determination of the monomer consumption by $\left.{ }^{1} \mathrm{H} \mathrm{NMR}\right)$ and $6 \mathrm{mg}(0.03 \mathrm{mmol})$ of AIBN were dissolved in $10 \mathrm{~mL}$ of DMF. The solution was poured in a $25 \mathrm{~mL}$ septum-sealed round-bottom flask and purged with argon for $30 \mathrm{~min}$ in an ice bath. $3.2 \mathrm{~mL}(31.0 \mathrm{mmol})$ of degassed DMAc were then injected into the flask via an air-tight syringe. The flask was then placed in a thermostated oil bath at $70{ }^{\circ} \mathrm{C}$. Aliquots were taken from the reaction media and analyzed by ${ }^{1} \mathrm{H}$ NMR to determine the monomer conversion. The polymerization was quenched by exposure to air and placing the flask into an ice bath. The polymer was precipitated in cold diethyl ether and dried under reduced vacuum at $50{ }^{\circ} \mathrm{C}$.

\section{RAFT copolymerization of acrylamide and acrylonitrile in presence of poly $(N, N$ - dimethylacrylamide) macroRAFT agents in water}

In a typical experiment (Table 2, entry 8$), 80 \mathrm{mg}(27 \mu \mathrm{mol})$ of PDMAc-TTC, $3.8 \mathrm{mg}(12 \mu \mathrm{mol})$ of VA-044 and $288 \mathrm{mg}(4.05 \mathrm{mmol})$ of AAm were dissolved in $1.64 \mathrm{~g}$ of water in a $4 \mathrm{~mL}$ round bottom flask. The resulting mixture was purged with argon for $15 \mathrm{~min}$ in a cold water bath. A 
solution of degassed $\mathrm{AN}(180 \mu \mathrm{L}, 2.75 \mathrm{mmol})$ in degassed water $(2.5 \mathrm{~mL})$ was then injected into the flask, through the septum into the reaction mixture. The flask was sealed with a Rotaflo teflon stopcock and immersed in a thermostated oil bath at $45^{\circ} \mathrm{C}$, and the polymerization lasted for $17 \mathrm{~h}$. The individual monomer conversions and the overall molar conversion at the end of the polymerization were determined by ${ }^{1} \mathrm{H}$ NMR.

\subsection{Characterization techniques}

${ }^{1} \mathrm{H}$ and ${ }^{13} \mathrm{C}$ NMR spectra were recorded in DMSO-d 6 at $300 \mathrm{~K}$ on a Bruker $300 \mathrm{MHz}$ spectrometer in 5-mm diameter tubes. For ${ }^{13} \mathrm{C}$ NMR measurements, the relaxation delay was set to $5 \mathrm{~s}$ and the spectrum was obtained in at least 7000 scans.

SEC measurements were carried out at $80{ }^{\circ} \mathrm{C}$ in DMSO $\left(+\mathrm{LiBr}, 1 \mathrm{~g} \mathrm{~L}^{-1}\right)$ as mobile phase at a flow rate of $0.7 \mathrm{~mL} \mathrm{~min}^{-1}$ and with toluene as a flow rate marker. All polymers were prepared at a concentration ranging from 5 to $10 \mathrm{mg} \mathrm{mL}^{-1}$ then filtered through a $0.45 \mu \mathrm{m}$ PTFE membrane; 100 $\mu \mathrm{L}$ of ready solution was injected for each measurement for analysis. The separation system was composed of two PSS GRAM $1000 \AA$ columns $\left(8 \times 300 \mathrm{~mm}\right.$; separation limits: 1 to $1000 \mathrm{~kg} \mathrm{~mol}^{-}$ ${ }^{1}$ ) and one PSS GRAM $30 \AA$ ( 8 x $300 \mathrm{~mm}$; separation limits: 0.1 to $\left.10 \mathrm{~kg} \mathrm{~mol}^{-1}\right)$ coupled with a modular differential refractive index (RI) detector Viscotek 3580. Molar masses $\left(M_{\mathrm{n}}\right.$, the numberaverage molar mass, $M_{\mathrm{w}}$, the weight-average molar mass) and dispersities $\left(\fallingdotseq=M_{\mathrm{w}} / M_{\mathrm{n}}\right)$ were calculated using OmniSEC 5.12 software with a calibration curve based on narrow Pullulan standards (from Polymer Standard Services).

Turbidimetry measurements of $\mathrm{P}(\mathrm{AAm}-\mathrm{co}-\mathrm{AN})$-based copolymers in water were performed on an Agilent spectrophotometer Cary $100 \mathrm{UV}$-Vis equipped with a Peltier-type temperature control system by measuring the transmittance at a wavelength of $670 \mathrm{~nm}$. The heating/cooling rate was 
maintained constant at $1{ }^{\circ} \mathrm{C} \min ^{-1}$. Samples were prepared at a concentration of $1 \mathrm{wt} \%$ by diluting the crude polymer dispersion in ultra-pure water (unless stated differently). All measurements were performed at natural $\mathrm{pH}$ without adjusting the ionization degree of the carboxylic acid chain end. The cloud point temperature $\left(\mathrm{T}_{\mathrm{CP}}\right)$ was determined at the inflection point.

DLS measurements were carried out on a Zetasizer Nano S90 from Malvern $\left(90^{\circ}\right.$ angle, $5 \mathrm{~mW} \mathrm{He}-$ Ne laser at $633 \mathrm{~nm})$ to determine the $\mathrm{z}$-average particle diameter $\left(\mathrm{D}_{\mathrm{z}}\right)$ of diluted dispersions in water.

Transmission Electron Microscopy (TEM) images were obtained by diluting the sample in ultrapure water at $0.03 \mathrm{wt} \%$ using phosphotungstic acid $(\mathrm{PhW})$ as contrast agent. A volume of $3 \mu \mathrm{L}$ was deposited on the grid and left to dry at ambient temperature for $1 \mathrm{~h}$. On the same grid, $3 \mu \mathrm{L}$ of a $0.05 \mathrm{wt} \% \mathrm{PhW}$ solution was deposited for $1 \mathrm{~min}$ then removed with a soft paper sheet. The grid was left to dry for at least 30 min before analysis. Images of particles were observed by a JEOL JEM 2011 microscope operating at $200 \mathrm{kV}$. The images were taken on a Gatan Orius CCD Camera. Cryogenic TEM (cryo-TEM) analyses: polymer solution was prepared at $1 \mathrm{wt} \%$ in ultra-pure water (unless otherwise stated). $3 \mu \mathrm{L}$ of the solution was then deposited on a quantifoil grid. After removing the excess of solution with a Whatman paper, the grid was immediately frozen in liquid ethane. The observations were carried out at $-180{ }^{\circ} \mathrm{C}$ by a JEOL JEM-2100 $\mathrm{LaB}_{6}$ microscope operating at $200 \mathrm{kV}$. The images were taken on a Gatan US 1000, 2k by 2k CCD Camera. 


\section{Results and discussion}

\subsection{Synthesis of PDMAc-b-P(AAm-co-AN) block copolymer in water}

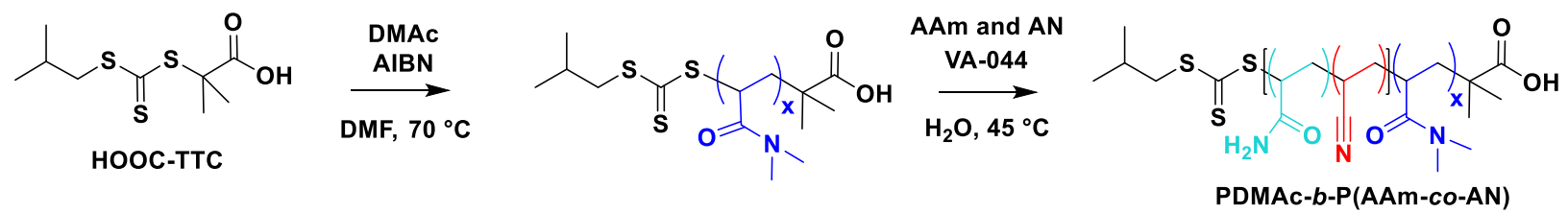

Scheme 1. Synthesis routes for the PDMAc macroRAFT agents and their subsequent chain extension with AAm and AN to produce PDMAc- $b$-P(AAm-co-AN) diblock copolymers via aqueous RAFT polymerization.

Before synthesizing thermoresponsive PDMAc- $b-\mathrm{P}(\mathrm{AAm}-\mathrm{co}-\mathrm{AN})$ block copolymer in water, we determined in a preliminary study the conditions that allowed synthesizing thermoresponsive $\mathrm{P}(\mathrm{AAm}-\mathrm{co}-\mathrm{AN})$ statistical copolymers in water using a molecular trithiocarbonate (TTC) RAFT agent, called HOOC-TTC (see Scheme S1). This preliminary study is described in details in Section I in the Supporting Information file. We demonstrated that the thermally-initiated RAFT copolymerization of AAm and $\mathrm{AN}$ conducted in water at $45^{\circ} \mathrm{C}$ (Table $\mathrm{S} 1$ and Figure $\mathrm{S} 2$ ) was well controlled, and showed that the statistical copolymers exhibited a typical UCST-type behavior which was strongly dependent on the molar fraction of the comonomers (Figure S4), as expected. ${ }^{53,61}$ In order to synthesize diblock copolymers possessing a hydrophilic poly $(N, N$ dimethylacrylamide) (PDMAc) block and a P(AAm-co-AN) block presenting a UCST behavior, we used the experimental conditions determined with HOOC-TTC, besides that a macromolecular RAFT agent (PDMAc-TTC) was used.

As illustrated in Scheme 1, in a first step, we synthesized poly $(N, N$-dimethylacrylamide) macromolecular RAFT agents (PDMAc-TTC) according to previously established protocols ${ }^{63,64}$, 
using HOOC-TTC, targeting a number-average degree of polymerization $\left(D P_{\mathrm{n}}\right)$ around 25 (Table S2). SEC analyses showed that macroRAFT agents with low molar mass dispersity were obtained, and the number-average molar masses determined by ${ }^{1} \mathrm{H}-\mathrm{NMR}, M_{\mathrm{n}, \mathrm{NMR}}$, were in good agreement with the theoretical values (Table S2) as expected in a controlled radical polymerization. The PDMAc-TTC macroRAFT agent was then used in the aqueous RAFT copolymerization of AAm and AN at $45{ }^{\circ} \mathrm{C}$. The targeted solids content $(\tau)$ (at quantitative monomer conversion) was limited to $10 \mathrm{wt} \%$ to guarantee the solubility of AN in the polymerization medium and thereby start the polymerizations under homogeneous conditions (the saturation concentration of AN in water is $7.35 \mathrm{wt} \%$ at $\left.20{ }^{\circ} \mathrm{C}\right)^{65}$. Two DP values were initially targeted (250 and 800$)$ with the molar fraction of $\mathrm{AN}$ in the feed $\left(\mathrm{f}_{\mathrm{AN}, 0}\right)$ varying from 0.35 to 0.65 (Table 1$)$. For the experiments targeting a low degree of polymerization (DP) of 250 (entries 8, 9 and 10 in Table 1), high conversions > 95\% were reached within $24 \mathrm{~h}$ (Table 1), whereas lower conversions were reached after the same time when a higher DP of 800 was targeted (entries 11 and 12 in Table 1). 
Table 1. Experimental conditions and results for aqueous copolymerizations of AAm and AN

in the presence of PDMAc macroRAFT agents (with $D P_{n}(P D M A c)=27$ or 23) performed at 10 wt $\%^{\#}$

\begin{tabular}{|c|c|c|c|c|c|c|c|c|c|c|c|c|}
\hline \multirow{2}{*}{ Entry } & \multirow{2}{*}{$\begin{array}{c}\text { Targeted } \\
\text { DP }\end{array}$} & \multirow{2}{*}{$\mathbf{f}_{\mathrm{AN}, 0^{a}}$} & \multirow{2}{*}{$\begin{array}{c}\text { Time } \\
\text { (h) }\end{array}$} & \multicolumn{3}{|c|}{$\operatorname{Conv}^{\mathbf{a}}(\%)$} & \multirow[t]{2}{*}{$\mathbf{F}_{\mathrm{AN}, \mathrm{NMR}}{ }^{\mathrm{a}}$} & \multirow[t]{2}{*}{$D P_{n, t h}{ }^{b}$} & \multirow[t]{2}{*}{$\begin{array}{c}\boldsymbol{M}_{\mathbf{n}, \mathbf{t h}} \mathbf{b}^{-1} \\
\left(\mathrm{~kg} \mathrm{~mol}^{-1}\right)\end{array}$} & \multirow[t]{2}{*}{$\begin{array}{c}\boldsymbol{M}_{\mathbf{n}, \mathbf{S E C}} \mathbf{c}^{\mathbf{c}} \\
\left(\mathrm{kg} \mathrm{mol}^{-1}\right)\end{array}$} & \multirow[t]{2}{*}{$\boldsymbol{D}^{\mathbf{c}}$} & \multirow[t]{2}{*}{$\begin{array}{l}\text { Mecha- } \\
\text { nism }^{\text {d }}\end{array}$} \\
\hline & & & & AN & AAm & Total & & & & & & \\
\hline $8^{\mathrm{e}}$ & & 0.35 & 17 & 99 & 96 & 97 & 0.36 & 243 & 15.5 & 20.9 & 1.25 & SP \\
\hline $9^{\mathrm{e}}$ & 250 & 0.50 & 20 & 99 & 93 & 96 & 0.52 & 240 & 15 & 20.8 & 1.21 & SP \\
\hline $10^{\mathrm{e}}$ & & 0.65 & 24 & 99 & 97 & 97 & 0.66 & 246 & 14.4 & 21.9 & 1.45 & $\mathrm{DP}^{*}$ \\
\hline $11^{\mathrm{f}}$ & 800 & 0.38 & 22 & 87 & 75 & 80 & 0.42 & 636 & 14.0 & 45.0 & 1.18 & SP \\
\hline $12^{\mathrm{f}}$ & & 0.65 & 24 & 96 & 76 & 89 & 0.70 & 712 & 44.1 & 32.4 & 2.38 & DP** \\
\hline
\end{tabular}

\#Polymerizations were performed in water at $45^{\circ} \mathrm{C}$ in presence of a macroRAFT agent (PDMAc-TTC) using VA-044 as a radical initiator at an initial molar ratio of PDMAc-TTC/VA-044: 1/0.3 at a targeted solids content of $10 \mathrm{wt} \%$.

${ }^{a}$ Determined by ${ }^{1} \mathrm{H}$ NMR analysis. ${ }^{\mathrm{b}}$ Theoretical number-average degree of polymerization, $D P_{\mathrm{n}, \mathrm{h}}$, and numberaverage molar mass, $M_{\mathrm{n}, \mathrm{h}}$, calculated using the experimental conversions. ${ }^{\mathrm{c}}$ Number-average molar mass $M_{\mathrm{n}}$ and dispersity, $\oslash$, determined by SEC in DMSO $\left(+\mathrm{LiBr}_{1 \mathrm{~g} \mathrm{~L}^{-1}}\right)$ with a Pullulan calibration. ${ }^{\mathrm{d}}$ Polymerization mechanism: $\mathrm{SP}=$ solution polymerization, $\mathrm{DP}=$ dispersion polymerization. ${ }^{\mathrm{e}}$ Polymerization performed in presence of a PDMAcTTC with a $D P_{\mathrm{n}}=27$ (entry M2 in Table S2). ${ }^{\mathrm{f}}$ Polymerization performed in presence of a PDMAc-TTC with a $D P_{\mathrm{n}}$ $=23$ (entry M1 in Table S2). Final aspect of the polymerization medium at $45^{\circ} \mathrm{C}$ : *turbid liquid, ** turbid gel.

The molar fraction of $\mathrm{AN}$ in the thermosensitive block, $\mathrm{F}_{\mathrm{AN}}$, was derived from the individual monomer conversions determined by ${ }^{1} \mathrm{H}$ NMR. ${ }^{13} \mathrm{C}-\mathrm{NMR}$ analyses performed on a representative purified sample (see Table $\mathrm{S} 3$ ) gave a similar $\mathrm{F}_{\mathrm{AN}}$ value validating thereby the former method. In order to get information on the microstructure of the copolymers, we monitored the individual monomer conversions with time in a representative copolymerization setting $\mathrm{f}_{\mathrm{AN}, 0}$ to 0.44 (see Figure S6, conditions comparable to experiment 11). We observed the expected difference in reactivity (reported in Chapiro and Perec-Spritzer's pioneering work ${ }^{59}$ ): AN was consumed more rapidly compared to AAm revealing a slight gradient within the polymer chains and an enrichment in AAm towards the P(AAm-co-AN) chain end. 
SEC analyses displayed in Figure S7, showed that, independently of the targeted DP and the $\mathrm{f}_{\mathrm{AN}}$ in the feed, a complete shift of the initial PDMAc macroRAFT agent signal towards higher molar masses was observed, indicating a quantitative extension of PDMAc-TTC with the formation of block copolymers. However, compared to the synthesis of the statistical P(AAm-co-AN) copolymers, the SEC traces were generally less narrow and sometimes asymmetric, which might be attributed to the prolonged polymerization times and the relatively high amount of initiator used, leading to an important fraction of dead chains. Whereas for low $\mathrm{f}_{\mathrm{AN}, 0}$ (experiments 8,9 and 11) molar mass dispersities $(\bigoplus)$ below 1.25 were obtained (see Table 1 ), for high $\mathrm{f}_{\mathrm{AN}, 0}=0.65$ (experiments 10 and 12) greater dispersities and SEC traces exhibiting shoulders at both high and low molar mass sides were actually obtained. It should be noted that these latter polymerizations (10 and 12) were turbid at the end of the polymerization at $45^{\circ} \mathrm{C}$, while transparent solutions were obtained for all other polymerizations (indicating a homogeneous solution polymerization, SP mechanism). The polymerizations (conducted at $45{ }^{\circ} \mathrm{C}$ ) proceed thus through a dispersion polymerization mechanism (DP), where the monomers are initially soluble and the formed copolymer is insoluble and assembles like in a typical PISA process. Whereas for experiment 10 a colloidally stable dispersion was obtained, for experiment 12, exhibiting an approximately threefold longer $\mathrm{P}(\mathrm{AAm}-\mathrm{co}-\mathrm{AN})$ block, a gel was obtained. The loss of polymerization control observed for this sample is certainly related to the gelation of the polymerization medium limiting the diffusion of species preventing the proper RAFT mechanism from occurring.

\subsection{Comparison of the $T_{C P}$ of statistical $P(A A m-c o-A N)$ and PDMAc-b-P(AAm-co-AN) diblock copolymers}


The thermoresponsive behavior of the PDMAc- $b-\mathrm{P}(\mathrm{AAm}-\mathrm{co}-\mathrm{AN})$ diblock copolymers in water was studied by turbidimetry and compared to the statistical $\mathrm{P}(\mathrm{AAm}-\mathrm{co}-\mathrm{AN})$ copolymers synthesized in the preliminary study (see Table 2). The results of the turbidimetry measurements are given in Figures S3 and S9. Whereas for the statistical copolymers the cloud point temperature ( $\mathrm{T}_{\mathrm{CP}}$ ) was tunable between $\sim 20{ }^{\circ} \mathrm{C}$ to $\sim 80{ }^{\circ} \mathrm{C}$ by increasing the molar fraction of $\mathrm{AN}\left(\mathrm{F}_{\mathrm{AN}}\right)$ in the copolymer (see also Figure S4), the presence of a hydrophilic block in the polymer structure generally caused a drastic decrease in the cloud point temperature. For example, comparing the statistical copolymers containing 32 or 40 mol\% of AN (entries 2 and 3 in Table 2) to the block copolymer containing $36 \mathrm{~mol} \%$ of $\mathrm{AN}$ in the second block (entry 8 in Table 2), the presence of the hydrophilic PDMAc block led to a drastic change in thermoresponsiveness. Indeed, no cloud point was observed for the block copolymer, the solution (at $1 \mathrm{wt} \%$ and 10\%) remained transparent even upon cooling to $0{ }^{\circ} \mathrm{C}$ (Figure $\mathrm{S} 8 \mathrm{~A}$ ). Such a decrease in $\mathrm{T}_{\mathrm{CP}}$ has also been reported in the literature comparing statistical $\mathrm{P}(\mathrm{AAm}-\mathrm{co}-\mathrm{AN})$ copolymers with the corresponding $\mathrm{PDMAc}_{425}-b$ $\mathrm{P}\left(\mathrm{AAm}_{231}\right.$-co- $\left.\mathrm{AN}_{78}\right)$ diblock copolymers (both synthesized in DMSO). ${ }^{66}$

When comparing different diblock copolymers with a targeted $D P_{\mathrm{n}}(\mathrm{P}(\mathrm{AAm}-\mathrm{co}-\mathrm{AN}))=250$, for the lowest $\mathrm{F}_{\mathrm{AN}}\left(\mathrm{F}_{\mathrm{AN}}=0.36\right.$, sample 8) no transition was detected as just mentioned. Cryo-TEM (not shown) and DLS (Figure S8B) analyses at room temperature confirmed that the diblock copolymer was molecularly dissolved in water (at least at room temperature and above) and did not present any typical UCST-like thermoresponsiveness. For higher $\mathrm{F}_{\mathrm{AN}}=0.52$ (sample 9, Figure S9A), by turbidimetry measurements at $1 \mathrm{wt} \%$ no clear transition was detected and DLS measurements confirmed that the chains were molecularly dissolved. In contrast, a distinct and reversible temperature-dependent change in transmittance was observed by turbidimetry performed at $11 \mathrm{wt} \%$ (Figure S9B). It might be explained by a UCST-like temperature-dependent 
aggregation/dissociation of individual chains, which is favored at higher concentration. Compared to the statistical copolymer with similar $\mathrm{F}_{\mathrm{AN}}$ (sample 5, see Figure $\mathrm{S} 3 \mathrm{D}$ ), the transition temperature was again greatly reduced. For the highest $\mathrm{AN}$ content $\left(\mathrm{F}_{\mathrm{AN}}=0.66\right.$, sample 10$)$, a turbid but stable dispersion was obtained, while the comparable statistical copolymer formed an insoluble precipitate in water (sample 6, Table S1). TEM and DLS measurements (Figure S10) of the diblock copolymer showed spherical aggregates, with an average diameter below $50 \mathrm{~nm}$. Turbidimetry analyses of the block copolymer revealed only a slight change in transmittance between 10 and 30 ${ }^{\circ} \mathrm{C}$ at $1 \mathrm{wt} \%$, but the concentrated sample (10 wt $\%$ ) showed a progressive but distinct transition between 10 and $40{ }^{\circ} \mathrm{C}$ (Figure S9C and D). For such high $\mathrm{F}_{\mathrm{AN}}$, we may assume that the P(AAmco-AN) block is too hydrophobic to allow a typical UCST behavior to occur involving chain dissociation and aggregation. Instead, a secondary aggregation of the initially formed particles should occur upon cooling, which is reversible and favored at high polymer concentration.

For longer $\mathrm{P}(\mathrm{AAm}-\mathrm{co}-\mathrm{AN})$ blocks (targeted $\mathrm{DP}=800$, samples 11 and 12), a clear impact of the $\mathrm{F}_{\mathrm{AN}}$ on the water-solubility and thermoresponsiveness was again observed. While for a high AN content (sample 12, with $\mathrm{F}_{\mathrm{AN}}=0.70$ ) a turbid gel was obtained that remained turbid over the whole temperature range, for sample 11 possessing a relatively low $\mathrm{F}_{\mathrm{AN}}\left(\mathrm{F}_{\mathrm{AN}}=0.42\right)$ a typical UCSTtype reversible temperature-induced aggregation and dissolution was observed by combined DLS (Figure S11) and turbidimetry analyses (Figure S9E). Comparing sample 11 with the corresponding statistical polymer of similar composition (sample 4), a drastic decrease in the transition temperature was again observed for the diblock copolymer. An increase of the length of the $\mathrm{P}(\mathrm{AAm}-\mathrm{co}-\mathrm{AN})$ block does thus not erase the impact of the PDMAc block on the temperature transition. 
Table 2. Comparison of the thermal characteristics of $\mathrm{P}(\mathrm{AAm}-\mathrm{co}-\mathrm{AN})$ statistical copolymers and PDMAc- $b$-P(AAm-co-AN) diblock copolymers

\begin{tabular}{|c|c|c|c|c|c|}
\hline Entry & RAFT agent & $\begin{array}{c}\text { Targeted } \\
\text { DP }^{\mathrm{a}}\end{array}$ & $\mathbf{F}_{\mathrm{AN}}{ }^{\mathbf{b}}$ & $D P_{n, t h}{ }^{b}$ & $\begin{array}{c}\text { TCP }_{\text {at }} 1 \mathrm{wt} \%{ }^{\mathrm{c}} \\
\text { in }{ }^{\circ} \mathrm{C}\end{array}$ \\
\hline \multicolumn{6}{|c|}{ P(AAm-co-AN) statistical copolymers } \\
\hline 2 & \multirow{5}{*}{ HOOC-TTC } & \multirow{5}{*}{200} & 0.32 & 162 & $17 / 21$ \\
\hline 3 & & & 0.40 & 157 & $38 / 42$ \\
\hline 4 & & & 0.43 & 147 & $65 / 69$ \\
\hline 5 & & & 0.52 & 122 & $\mathrm{NO}(76 / 79)^{\mathrm{d}}$ \\
\hline 6 & & & 0.69 & 154 & N.D.* \\
\hline \multicolumn{6}{|c|}{ PDMAc-b-P(AAm-co-AN) diblock copolymers } \\
\hline 8 & & & 0.36 & 243 & NO \\
\hline 9 & $\mathrm{PDMAC}_{27}-\mathrm{TTC}$ & 250 & 0.52 & 240 & $\mathrm{NO}(14 / 26)^{\mathrm{e}}$ \\
\hline 10 & & & 0.66 & 246 & $\mathrm{NO}(33 / 34)^{\mathrm{e}}$ \\
\hline 11 & & & 0.42 & 636 & $26 / 29$ \\
\hline 12 & $\mathrm{PDMAC}_{23}-\mathrm{TTC}$ & 800 & 0.70 & 712 & N.D.* \\
\hline
\end{tabular}

${ }^{a}$ Targeted DP of the P(AAm-co-AN) block. ${ }^{b}$ Determined by ${ }^{1} \mathrm{H}$ NMR analysis. ${ }^{c}$ Determined in water by turbidimetry at $1 \mathrm{wt} \%$, on $1^{\text {st }}$ cooling $/ 2^{\text {nd }}$ heating. ${ }^{\mathrm{d}}$ Analysis performed at $0.2 \mathrm{wt} \%$ (sample 5). ${ }^{\mathrm{e}}$ Analysis performed at $11 \mathrm{wt} \%$ (sample 9) and $10 \mathrm{wt} \%$ (sample 10). N.D.: not determined. * Not dispersible. NO: no distinct transition observed between 10 and $80{ }^{\circ} \mathrm{C}$.

As mentioned above, polymerizations 10 and 12 were turbid at the end of the polymerization at 45 ${ }^{\circ} \mathrm{C}$. Thus, the polymerizations (conducted at $45^{\circ} \mathrm{C}$ ) proceed through a dispersion polymerization mechanism. Based on combined analyses of sample 10 by SEC, DLS, TEM and turbidimetry, we can reasonably assume that amphiphilic copolymers are actually formed that assemble during polymerization into micellar aggregates stabilized by the hydrophilic PDMAc block, just as it happens in a typical polymerization-induced self-assembly (PISA) process. At sufficient high $\mathrm{F}_{\mathrm{AN}}$, the copolymerization of AN and AAm in water at $45^{\circ} \mathrm{C}$ can thus produce thermoresponsive block copolymer particles through PISA. 


\subsection{Influence of the length of the P(AAm-co-AN) block on morphologies obtained by PISA}

It is well-known that the particle morphology (mainly spheres, worms/fibers or vesicles) during a typical PISA process can be tuned by the block lengths - via the packing parameter ${ }^{67-69}$ - provided that chain reorganization and particle fusion are possible. Otherwise, only spherical particles are obtained..$^{70-72}$ In order to know if the formation of higher order morphologies is possible with PDMAc- $b$-P(AAm-co-AN) block copolymers in water, we studied the influence of the length of the $\mathrm{P}(\mathrm{AAm}-\mathrm{co}-\mathrm{AN})$ block by keeping constant the length of the hydrophilic block $\left(D P_{\mathrm{n}}(\mathrm{PDMAc}-\right.$ TTC) $=27$ ). In order to perform the polymerizations under PISA conditions in dispersion, all polymerizations were done at high constant initial $\mathrm{f}_{\mathrm{AN}}$ of 0.65 at $45^{\circ} \mathrm{C}$ (in order to form copolymers having a $\mathrm{T}_{\mathrm{CP}}$ above the polymerization temperature), keeping constant the targeted solids content at $\sim 10 \mathrm{wt} \% .^{\dagger}$ As shown in Table 3, all RAFT polymerizations reached a high overall molar conversion (generally $\geq 89 \%$ ) within 24 h of reaction. The size exclusion chromatograms in Figure $\mathrm{S} 12$ revealed a good blocking efficiency, with molar mass dispersities below 1.6 as long as a DP $\leq$ 760 was targeted (Table 3). However, a significant tailing toward the lower molar mass side was observed. Again, this limited polymerization control should be attributed to the high [initiator]/[macroRAFT] ratio used combined with the prolonged polymerization times, thereby promoting termination reactions. Generally, the dispersity increased when increasing DP of the hydrophobic block, presumably due to side reactions that are favored for longer polymer blocks. Another explanation could rely on differences in the copolymer assembly and sample viscosity limiting diffusion. Indeed, with increasing DP of the $\mathrm{P}(\mathrm{AAm}-\mathrm{Ao}-\mathrm{AN})$ block, the aspect of the final dispersions changed (see Table 3); strong differences in viscosity and turbidity were observed.

\footnotetext{
${ }^{\dagger}$ Solids content at $100 \%$ monomer conversion: $[\mathrm{m}(\mathrm{PDMAc}-\mathrm{TTC})+\mathrm{m}(\mathrm{AN})+\mathrm{m}(\mathrm{AAm})] / \mathrm{m}($ total $) \times 100$
} 
While the polymer dispersion with the smaller targeted DP (DP $=250$, entry 10 in Table 3$)$ was liquid and turbid and remained colloidally stable, for higher targeted DP (510 and 760) an important increase in viscosity was observed. For even higher targeted DP (DP $=1270$, entry 15 in Table 3$)$ the polymerization medium phase-separated into a gel-like phase and an excluded liquid phase, that could not be redispersed in water, indicating the coalescence of individual particles due to insufficient stabilization.

Table 3. Experimental conditions and properties of the UCST-type copolymers prepared at $10 \mathrm{wt} \%$ in dispersion polymerization conditions by PISA in water ${ }^{\#}$

\begin{tabular}{|c|c|c|c|c|c|c|c|c|c|c|c|c|}
\hline \multirow{2}{*}{ Entry } & \multirow{2}{*}{$\begin{array}{c}\text { Targeted } \\
\text { DP }\end{array}$} & \multicolumn{3}{|c|}{$\operatorname{Conv}(\%)^{\mathrm{a}}$} & \multirow{2}{*}{$\mathbf{F}_{\mathrm{AN}}{ }^{\mathbf{a}}$} & \multirow{2}{*}{$D P_{\mathrm{n}, \mathrm{th}}{ }^{\mathrm{b}}$} & \multirow{2}{*}{$\begin{array}{c}M_{n \mathrm{th}^{\mathrm{b}}} \\
\left(\mathrm{kg} \cdot \mathrm{mol}^{-1}\right)\end{array}$} & \multirow{2}{*}{$\begin{array}{c}M_{\mathrm{n}, \mathrm{SEC}}{ }^{\mathrm{c}} \\
\left(\mathrm{kg} \mathbf{m o l}^{-1}\right)\end{array}$} & \multirow{2}{*}{$\boldsymbol{D}^{\mathbf{c}}$} & \multirow{2}{*}{$\begin{array}{c}\text { Final aspect } \\
\left(45^{\circ} \mathrm{C}\right)\end{array}$} & \multirow{2}{*}{$\begin{array}{l}\mathbf{T T}^{\mathbf{d}} \\
\left({ }^{\circ} \mathbf{C}\right)\end{array}$} & \multirow{2}{*}{$\begin{array}{c}\text { Morphology } \\
\text { (size in } \\
\text { diameter) }\end{array}$} \\
\hline & & $\mathrm{AN}$ & AAm & Total & & & & & & & & \\
\hline 10 & 250 & 99 & 97 & 97 & 0.66 & 246 & 14.4 & 21.9 & 1.45 & Turbid liquid & $\begin{array}{c}\text { NO } \\
(33 / 34)^{\mathrm{f}}\end{array}$ & $\begin{array}{l}\text { Sphere }^{\#} \\
(20-30 \mathrm{~nm})\end{array}$ \\
\hline 13 & 510 & 98 & 91 & 96 & 0.65 & 487 & 25.5 & 37.0 & 1.53 & Milky gel & $33 / 34$ & $\begin{array}{l}\text { Worm } \\
(\sim 20 \mathrm{~nm})\end{array}$ \\
\hline 14 & 760 & 96 & 75 & 89 & 0.70 & 673 & 34.0 & 43.4 & 1.59 & $\begin{array}{c}\text { Turbid viscous } \\
\text { liquid }\end{array}$ & $37 / 40$ & $\begin{array}{l}\text { Worm } \\
(\sim 20 \mathrm{~nm})\end{array}$ \\
\hline 15 & 1270 & 94 & 71 & 86 & 0.71 & 1092 & 53.0 & 72.6 & 2.27 & $\begin{array}{l}\text { Gel + turbid } \\
\text { liquid phase }\end{array}$ & N.D* & N.D \\
\hline $16^{\mathrm{g}, \mathrm{h}}$ & 800 & 93 & 84 & 89 & 0.53 & 708 & 34.0 & 57.4 & 1.19 & $\begin{array}{l}\text { Slightly turbid } \\
\text { viscous liquid }\end{array}$ & $\begin{array}{c}\text { NO } \\
(30 / 33)^{\mathrm{e}}\end{array}$ & Worm \\
\hline
\end{tabular}

${ }^{\#}$ Polymerizations were performed in water at $45{ }^{\circ} \mathrm{C}$ for $24 \mathrm{~h}$ in presence of PDMAc $27-\mathrm{TTC}$ using VA-044 as a radical initiator at an initial molar ratio of PDMAc-TTC/initiator: 1/0.3 at targeted solids contents of $10 \mathrm{wt} \%$, with a constant initial $\mathrm{f}_{\mathrm{AN}}$ of 0.65 . a Determined by ${ }^{1} \mathrm{H}$ NMR. ${ }^{\mathrm{b}} D P_{\mathrm{n}}$ of the $\mathrm{P}(\mathrm{AAm}-\mathrm{co}-\mathrm{AN})$ block and total $M_{\mathrm{n}}$ determined via the monomer conversion. ${ }^{c}$ Number-average molar mass $M_{\mathrm{n}, \mathrm{SEC}}$ and dispersity, $Ð$, determined by SEC in DMSO $(+\mathrm{LiBr}$ $1 \mathrm{~g} \mathrm{~L}^{-1}$ ) with a Pullulan calibration. ${ }^{\mathrm{d}} \mathrm{TT}=$ Thermal transition determined by turbidimetry in water at $1 \mathrm{wt} \%$ on $1^{\text {st }}$ cooling $/ 2^{\text {nd }}$ heating. ${ }^{\mathrm{e}}$ Morphology observed by cryo-TEM after dilution in water at $1 \mathrm{wt} \%$, except for sample $14(0.3$ $\left.{ }_{\mathrm{wt}} \%\right) .{ }^{\mathrm{f}}$ Thermal transition determined by turbidimetry in water at $10 \mathrm{wt} \%$ on $1^{\text {st }}$ cooling $/ 2^{\text {nd }}$ heating. ${ }^{\mathrm{g}}$ Initial $\mathrm{f}_{\mathrm{AN}}=$ 
0.50. ${ }^{\mathrm{h}}$ Polymerization performed in presence of PDMAc 23 -TTC. N.D: not determined. NO: no transition observed between 10 and $80{ }^{\circ} \mathrm{C} . *$ Not dispersible. ${ }^{\#}$ Morphology observed by TEM after dilution in water at 0.03 wt $\%$.

The assembly of the block polymers was studied by TEM. As already mentioned above (Section 3.2), spherical micelles were obtained for the PDMAc- $b-\mathrm{P}(\mathrm{AAm}-\mathrm{co}-\mathrm{AN})$ diblock copolymer with the lowest $D P_{\mathrm{n}}$ (sample $10, D P_{\mathrm{n}}=246$ for the UCST-like block; Figure S10). For longer P(AAmco-AN) blocks $\left(D P_{\mathrm{n}} \sim 500\right.$ and 700, entry 13 and 14 in Table 3), short worms were produced (Figure S13), which explains the observed viscosity of the sample. Further increase of the hydrophobic block length might result in the production of vesicles through the modification of the packing parameter, ${ }^{72-74}$ however in the present system, increasing the length of the $\mathrm{P}(\mathrm{AAm}-\mathrm{co}$ $\mathrm{AN}$ ) block led to the formation of a phase-separated gel, which was not dispersible in water (entry 15 in Table 3) and could not be analyzed by TEM.

It has been reported that the presence of hydrophilic monomers in the hydrophobic block in PISA favors the formation of higher-order morphologies. ${ }^{75}$ An additional experiment was therefore performed reducing the amount of hydrophobic acrylonitrile content to $53 \mathrm{~mol} \%$ for a targeted DP of the P(AAm-co-AN) block equal to 800 (entry 16 in Table 3). These conditions should still lead to a $\mathrm{T}_{\mathrm{CP}}$ above the polymerization temperature and allow the formation of assemblies in a PISAtype polymerization process. After $24 \mathrm{~h}$ of reaction at $45^{\circ} \mathrm{C}$, a slightly turbid, viscous dispersion was obtained. As shown in Figure 1, the appearance of the reaction medium and particle morphology changed drastically with increasing monomer conversion. Indeed, while a clear liquid solution was observed at $3 \mathrm{~h}$ of reaction, the medium was a milky gel at $9 \mathrm{~h}$ and a viscous slightly turbid dispersion was obtained after $24 \mathrm{~h}$. Cryo-TEM analyses revealed the presence of spherical particles at $3 \mathrm{~h}$ of reaction, which evolved towards worms during the polymerization process. 

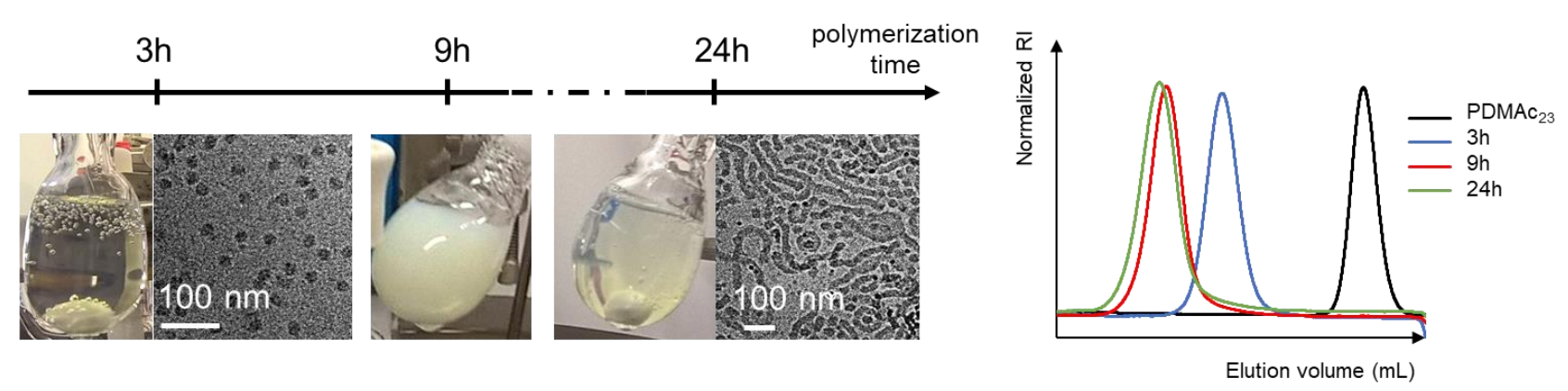

Figure 1. Evolution of the reaction medium (at $45{ }^{\circ} \mathrm{C}$ ), morphologies and size exclusion chromatograms during the dispersion polymerization of AAm and AN using PDMAc 23-TTC (entry $16 ; \mathrm{f}_{\mathrm{AN}, 0}=0.5$, targeted $\left.\mathrm{DP}=800\right)$.

\subsection{Influence of the temperature on morphologies obtained by PISA}

Turbidimetry was used to assess whether the samples obtained in PISA conditions (using high $f_{A N, 0}$ ) showed temperature-responsive behavior (samples 10 and 13 to 16 , in Table 3 ). While the dispersion of the copolymer with the shortest $\mathrm{P}(\mathrm{AAm}-\mathrm{co}-\mathrm{AN})$ block $\left(D P_{\mathrm{n}}=246\right.$, entry 10 in Table 3) exhibited no clear transition at $1 \mathrm{wt} \%$, a clear temperature transition was observed at high polymer concentration (10 wt\%, Figure S9), as discussed before. In contrast, for samples 13 and 14 with longer $\mathrm{P}(\mathrm{AAm}-\mathrm{co}-\mathrm{AN})$ blocks $\left(D P_{\mathrm{n}, \text { th }}=487\right.$ and 673$)$ a large thermal transition between 20 and $40{ }^{\circ} \mathrm{C}$ was already observed at low polymer concentration ( $1 \mathrm{wt} \%$, see Figure S14). These three samples, containing about $70 \mathrm{~mol} \%$ of AN in the UCST-type block are rather hydrophobic, and therefore do not dissociate into individual polymer chains over the whole temperature range in water, as confirmed by DLS measurements. While sample 10 contains spherical particles, the morphology of sample 13 and 14 determined by cryo-TEM are worm-like particles, independent of the temperature of analysis. The observed reversible temperature response must thus be 
attributed to a more complex transition, which should involve secondary aggregation of primary particles (upon cooling) and their reversible dissociation (upon heating).

A different behavior was observed for sample 16 , exhibiting a high DP $\left(D P_{\mathrm{n}, \text { th }}=708\right)$, but a lower AN content. Macroscopically a significant change in viscosity was observed when the pristine sample at $10 \mathrm{wt} \%$ was heated. At $4{ }^{\circ} \mathrm{C}$ the sample was a free-standing gel, which started to flow above $25^{\circ} \mathrm{C}$. The viscosity as well as the sample turbidity progressively decreased upon heating to $60{ }^{\circ} \mathrm{C}$, indicate a change in chain assembly. Turbidity analyses of the dispersion revealed also the presence of a large thermal transition in the same temperature range (Figures $2 \mathrm{~A}$ and $2 \mathrm{~B}$ ), but the reversibility of the thermal transition was concentration dependent; at $10 \mathrm{wt} \%$ reversible, but at 1 $\mathrm{wt} \%$ the transition was irreversible and faded after the first heating cycle. The transmittance was still low after the transition (around 0.7 in this case), indicating that after a thermal cycle light scattering entities were still present in the sample and no true dissolution of the chains occurred. We therefore analyzed sample 16 by cryo-TEM: the pristine dispersion containing worms was diluted to $1 \mathrm{wt} \%$, heated at $70{ }^{\circ} \mathrm{C}$, and cooled down at room temperature; which corresponds to the heat treatment that the samples received during the analysis by turbidimetry. As shown in Figures $2 \mathrm{C}$ and $\mathrm{D}$, upon heating, the initial worms with a number-average diameter, $\mathrm{D}_{\mathrm{n}, \mathrm{TEM}}=24 \mathrm{~nm}$ undergo a morphological transition towards spheres with an average diameter of $27 \mathrm{~nm}$. These smaller objects scatter less light, which explain the observed increase in transmittance. For the same dispersion after heating to $70{ }^{\circ} \mathrm{C}$ and cooling at room temperature, we still observed the presence of spheres with a comparable diameter $\mathrm{D}_{\mathrm{n}, \mathrm{TEM}}$ of $26 \mathrm{~nm}$ (Figure 2E). These results show that, at this concentration (1 wt \%), this morphological transition is irreversible. When the pristine dispersion (at $10 \mathrm{wt} \%$ ) was heated to $70{ }^{\circ} \mathrm{C}$, we observed again the formation of spheres (Figure S15A); however, when this concentrated solution was cooled down to room temperature (the 
sample was diluted only prior to cryo-TEM sample preparation to $1 \mathrm{wt} \%$ ), we still observed the presence of some worms in the sample (Figure S15B). At this concentration, the morphological transition from worms to spheres (W-to-S) is at least partially reversible. Temperature-induced morphological transitions have already been observed in the literature for PISA-derived particles, but never for UCST-like polymers. ${ }^{76-79}$ Such morphological transitions have been explained by an interfacial hydration of the core block inducing a subtle decrease in the packing parameter. ${ }^{79,80}$ Generally, in water the observed transition is a LCST-like one, where the core-chain become less hydrated above heating, leading to the formation of higher-order morphologies. To our knowledge, W-to-S transition upon heating were only reported in non-polar media. ${ }^{81-84}$ In contrast, here the increase of temperature leads to an increase of core hydration leading to the formation of spherical particles instead of higher order morphologies.

These results showed that it was possible to synthesize block copolymers with a UCST-type block by PISA in water and that the formed nano-objects can undergo a temperature-induced morphological transition whose reversibility is concentration-dependent. 


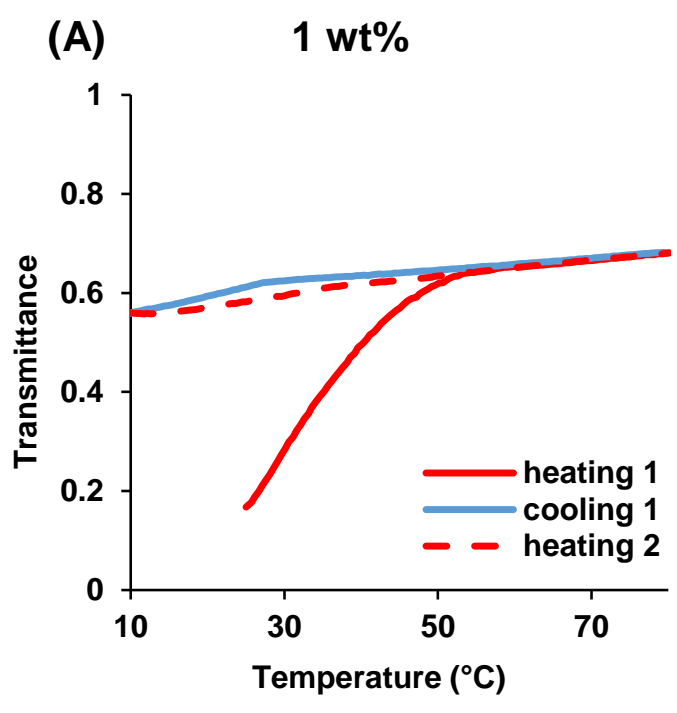

(C)

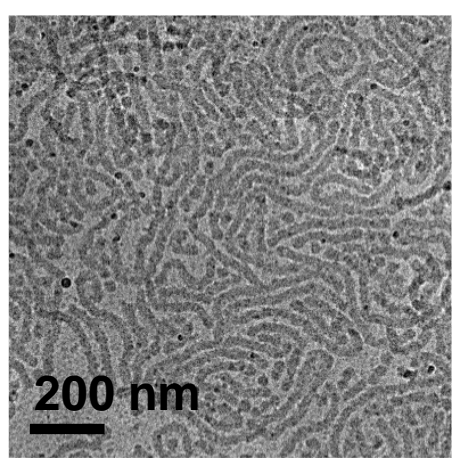

(D)

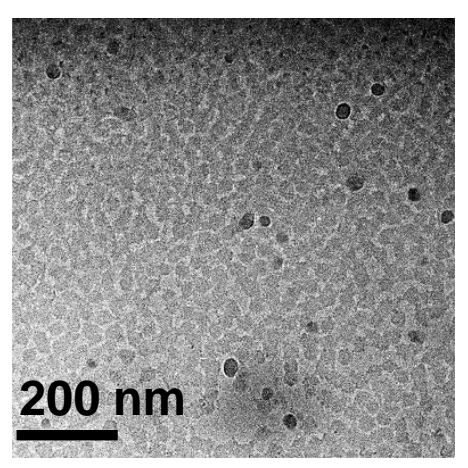

(F)

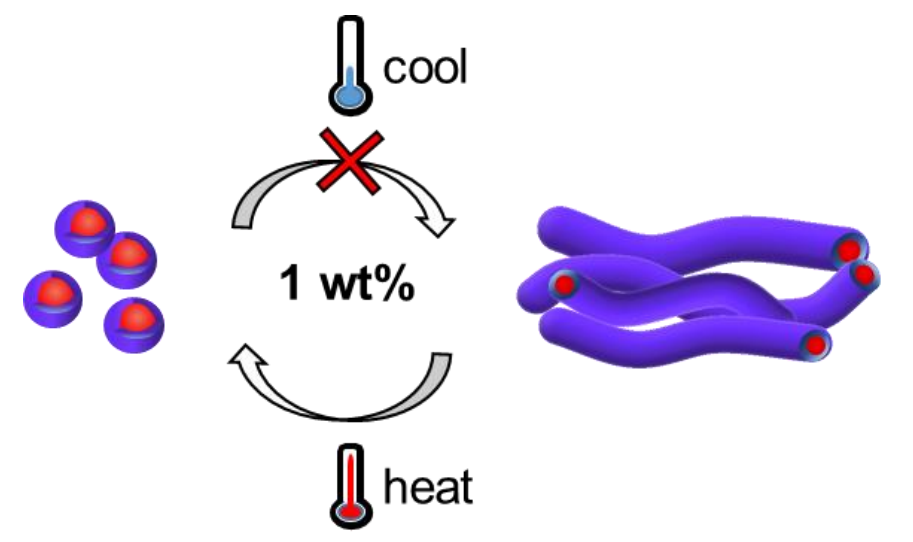

(E)

(B) $10 w t \%$
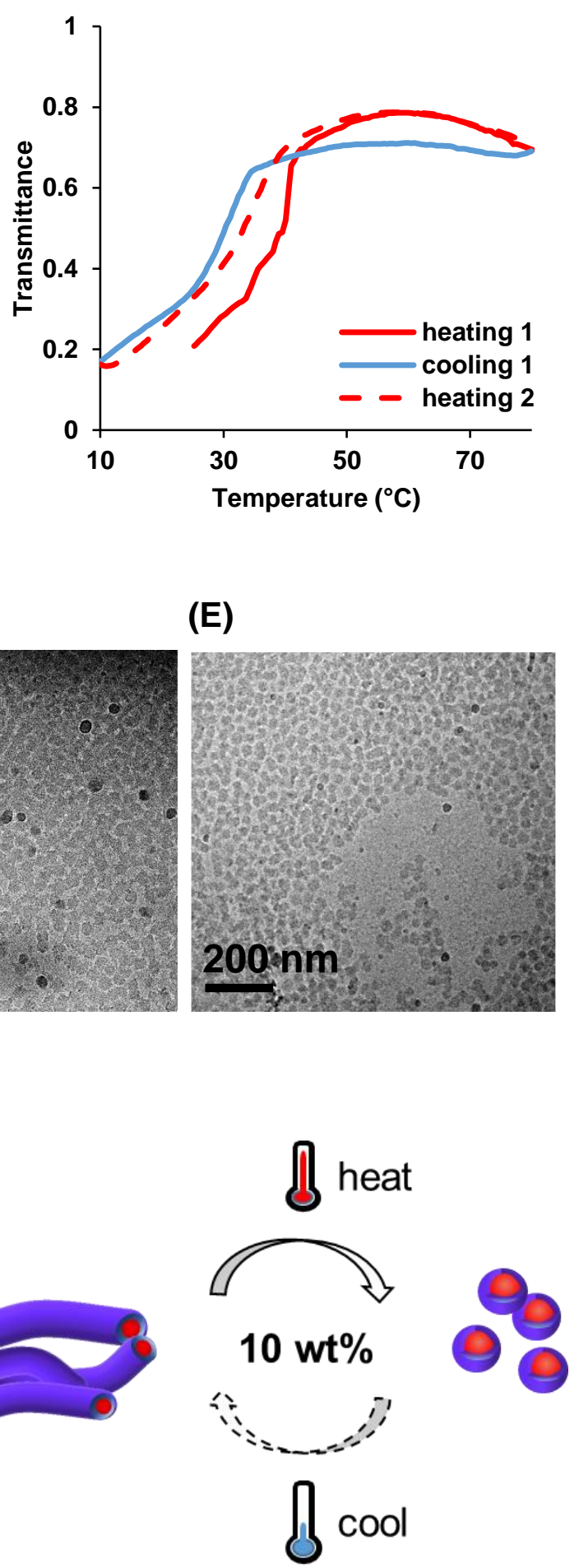

Figure 2. Turbidimetry curves (first heating, first cooling and second heating) of a PDMAc- $b$ $\mathrm{P}(\mathrm{AAm}-\mathrm{co}-\mathrm{AN})$ dispersion sample 16 at (A) $1 \mathrm{wt} \%$ and (B) $10 \% \mathrm{wt}$ in water and representative cryo-TEM image of the (C) pristine sample at $1 \mathrm{wt} \%$, (D) same dispersion heated and analyzed at 
$70{ }^{\circ} \mathrm{C}$ and (E) same dispersion after heating at $70{ }^{\circ} \mathrm{C}$ and cooling at room temperature. (F) Cartoon depicting the morphology change occurring upon temperature modification at different concentrations.

\section{Discussion and conclusions}

We have developed a straightforward strategy to synthesize in water well-defined P(AAm-co-AN) statistical copolymers and PDMAc- $b$-P(AAm-co-AN) diblock copolymers of various compositions, using a trithiocarbonate RAFT agent combined to a thermal initiator. The P(AAmco-AN) statistical copolymers exhibit a typical UCST-type thermal transition, and the transition temperature increased with increasing molar fraction of $\mathrm{AN}\left(\mathrm{F}_{\mathrm{AN}}\right)$ and increasing polymer concentration, as expected. Such UCST behavior was generally observed for $0.3 \leq \mathrm{F}_{\mathrm{AN}} \leq 0.5$, whereas for much higher and much lower $\mathrm{F}_{\mathrm{AN}}$, insoluble or completely soluble polymers with no notable temperature-response were obtained.

PDMAc- $b$-P(AAm-co-AN) diblock copolymers were also obtained with good polymerization control. The combined analysis of the aqueous polymer solutions by DLS, turbidimetry and (cryo)TEM revealed that their thermoreponsiveness was much more complex than that of the statistical copolymers and greatly dependent on the $\mathrm{F}_{\mathrm{AN}}$ and the $D P_{\mathrm{n}}$ of the UCST-block, as proposed in Figure 3. Again, soluble polymers exhibiting no noticeable thermoresponsiveness were observed for low $\mathrm{F}_{\mathrm{AN}}$, while diblock copolymers with intermediate $\mathrm{F}_{\mathrm{AN}}$ exhibited a temperature-dependent dissociation/aggregation into micellar particles stabilized by the PDMAc block. For high $\mathrm{F}_{\mathrm{AN}}$ colloidally stable particles were formed during polymerization, provided that $D P_{\mathrm{n}} \leq 800$. They do not dissociate into individual chains upon heating, but we rather evidenced that at low temperature clusters of individual particles are formed by a secondary aggregation mechanism that dissociate into individual particles upon heating. Interestingly, for such high $\mathrm{F}_{\mathrm{AN}}$, the polymerization 
mechanism is that of a typical PISA mechanism, where the chain growth and the formed amphiphilic diblock copolymer assembles in situ into core-shell aggregates, of which the morphology was tunable by the $D P_{\mathrm{n}}$ of the $\mathrm{P}(\mathrm{AAm}-\mathrm{co}-\mathrm{AN})$ block. Thanks to this polymerization strategy performed at $10 \mathrm{wt} \%$ in water, we were able to synthesize for the first time worm-like micelles constituted of a P(AAm-co-AN) UCST-block.

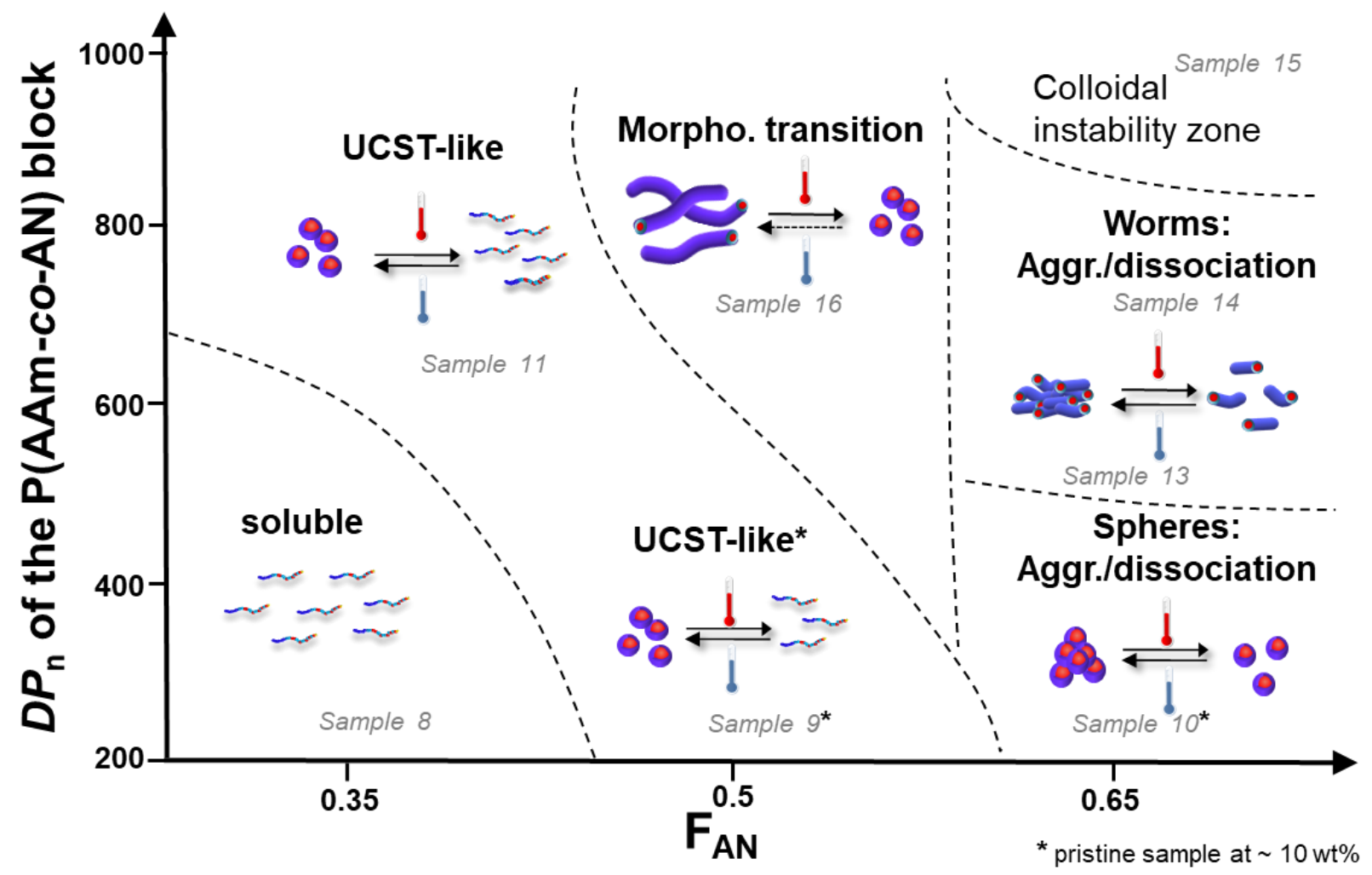

Figure 3. Attempt to rationalize the thermoresponsiveness of PDMAc- $b-\mathrm{P}(\mathrm{AAm}-c o-\mathrm{AN})$ diblock copolymers synthesized by RAFT (PISA) in water.

Importantly, for intermediate $\mathrm{F}_{\mathrm{AN}}$ and high $D P_{\mathrm{n}}$, worms were formed that undergo upon heating an unprecedented worm-to-sphere (W-to-S) morphological transition, which was explained by an increased hydration of the core block. While several previous reports have already mentioned temperature-induced morphology changes in aqueous media, they generally produced higher-order 
morphologies upon heating. ${ }^{76-79}$ Therefore, to the best of our knowledge, the PDMAc- $b$-P(AAmco-AN) diblock copolymers is the first system that presents, at fixed composition in aqueous media, a worm-to-sphere order-order transition upon temperature increase in water. We believe that the developed synthesis of core-shell structures exhibiting a UCST core by PISA will be a promising strategy to design a great number of intelligent nanomaterials for various applications.

\section{Acknowledgements}

The authors thank the LabEX MiChem for funding (FILOMAG project) and Patricia Beaunier (LRS, Sorbonne Université) for TEM analyses.

Keywords: Aqueous RAFT polymerization, UCST, block copolymers, PISA

\section{References}

1 A. Bordat, T. Boissenot, J. Nicolas and N. Tsapis, Adv. Drug Deliv. Rev., 2019, 138, 167-192.

2 D. Roy, W. L. A. Brooks and B. S. Sumerlin, Chem. Soc. Rev., 2013, 42, 7214-7243.

3 C. Zhao, Z. Ma and X. X. Zhu, Prog. Polym. Sci., 2019, 90, 269.

4 D. Roy, J. N. Cambre and B. S. Sumerlin, Prog. Polym. Sci., 2010, 35, 278-301.

5 M. A. C. C. Stuart, W. T. S. S. Huck, J. Genzer, M. Müller, C. Ober, M. Stamm, G. B. Sukhorukov, I. Szleifer, V. V. Tsukruk, M. Urban, F. Winnik, S. Zauscher, I. Luzinov and S. Minko, Nat. Mater., 2010, 9, 101-113.

6 M. A. Ward and T. K. Georgiou, Polymers (Basel)., 2011, 3, 1215-1242.

7 O. Sedlacek, D. Bera and R. Hoogenboom, Polym. Chem., 2019, 10, 4683-4689.

8 I. C. Barker, J. M. G. Cowie, T. N. Huckerby, D. A. Shaw, I. Soutar and L. Swanson, Macromolecules, 2003, 36, 7765-7770.

9 Z. Lu, Z. Zhang and Y. Tang, ACS Appl. Bio Mater., 2019, 2, 4485-4492.

10 J. Seuring and S. Agarwal, Macromol. Rapid Commun., 2012, 33, 1898-1920.

11 J. Niskanen and H. Tenhu, Polym. Chem., 2017, 8, 220-232. 
J. Seuring and S. Agarwal, ACS Macro Lett., 2013, 2, 597-600.

V. Albright, A. Palanisamy, Q. Zhou, V. Selin and S. A. Sukhishvili, Langmuir, 2019, 35, 1067710688 .

K. K. Bansal, P. K. Upadhyay, G. K. Saraogi, A. Rosling and J. M. Rosenholm, express Polym. Lett., 2019, 13, 974-992.

R. Rajan and K. Matsumura, Macromol. Rapid Commun., 2017, 38, 1700478.

F. Han, A. H. Soeriyadi and J. J. Gooding, Macromol. Rapid Commun., 2018, 39, 1800451.

W. Fu, C. Luo, E. A. Morin, W. He, Z. Li and B. Zhao, ACS Macro Lett., 2017, 6, 127-133.

J. Ning, K. Kubota, G. Li and K. Haraguchi, React. Funct. Polym., 2013, 73, 969-978.

P. A. Woodfield, Y. Zhu, Y. Pei and P. J. Roth, Macromolecules, 2014, 47, 750-762.

T. Maji, S. Banerjee, Y. Biswas and T. K. Mandal, Macromolecules, 2015, 48, 4957-4966.

L. D. Blackman, P. A. Gunatillake, P. Cass and K. E. S. Locock, Chem. Soc. Rev., 2019, 48, 757770 .

F. Liu, J. Seuring and S. Agarwal, Polym. Chem., 2013, 4, 3123-3131.

J. Seuring, F. M. Bayer, K. Huber and S. Agarwal, Macromolecules, 2012, 45, 374-384.

X. Xue, L. Thiagarajan, S. Braim, B. R. Saunders, K. M. Shakesheff and C. Alexander, J. Mater. Chem. B, 2017, 5, 4926-4933.

Z. Xu and W. Liu, Chem. Commun., 2018, 54, 10540-10553.

W. Sun, Z. An and P. Wu, Macromolecules, 2017, 50, 2175-2182.

F. Käfer, A. Lerch and S. Agarwal, J. Polym. Sci. Part A Polym. Chem., 2017, 55, 274-279.

S. Glatzel, A. Laschewsky and J. F. Lutz, Macromolecules, 2011, 44, 413-415.

F. Liu, J. Seuring and S. Agarwal, J. Polym. Sci. Part A Polym. Chem., 2012, 50, 4920-4928.

N. Shimada, T. Sasaki, T. Kawano and A. Maruyama, Biomacromolecules, 2018, 19, 4133-4138.

A. Fujihara, N. Shimada, A. Maruyamam, K. Ishihara, K. Nakai and S. S. Yusa, Soft Matter, 2015, 11, 5204-5213.

S. Kuroyanagi, N. Shimada, S. Fujii, T. Furuta, A. Harada, K. Sakurai and A. Maruyama, J. Am. Chem. Soc., 2019, 141, 1261-1268.

N. Shimada, H. Ino, K. Maie, M. Nakayama, A. Kano and A. Maruyama, Biomacromolecules, 2011, 12, 3418-3422.

F. Käfer, M. Pretscher and S. Agarwal, Macromol. Rapid Commun., 2018, 39, 1800640.

A. Asadujjaman, T. Espinosa De Oliveira, D. Mukherji and A. Bertin, Soft Matter, 2018, 14, 13361343.

Z. Zhang, H. Li, S. Kasmi, S. Van Herck, K. Deswarte, B. Lambrecht, R. Hoogenboom, L. Nuhn and B. de Geest, Angew. Chemie - Int. Ed., 2019, 58, 7866-7872.

B. A. Pineda-Contreras, F. Liu and S. Agarwal, J. Polym. Sci. Part A Polym. Chem., 2014, 52, 1878- 
1884.

C. Echeverria and C. Mijangos, Langmuir, 2011, 27, 8027-8035.

C. Zhao, L. Dolmans and X. X. Zhu, Macromolecules, 2019, 52, 4441-4446.

G. Tong, Z. Fang, G. Huang, Y. Jing, S. Dai, Q. Jiang, C. Zhang, S. T. Feng and Z. P. Li, RSC Adv., 2016, 6, 50534-50542.

M. Qi, K. Li, Y. Zheng, T. Rasheed and Y. Zhou, Langmuir, 2018, 34, 3058-3067.

W. J. Zhang, C. Y. Hong and C. Y. Pan, Biomacromolecules, 2016, 17, 2992-2999.

J. Wang, Z. Wu, G. Wang and K. Matyjaszewski, Macromol. Rapid Commun., 2019, 40, 1800332.

L. Meng, X. Ma, S. Jiang, G. Ji, W. Han, B. Xu, J. Tian and W. Tian, J. Mater. Chem. B, 2019, 5, $5345-5351$.

W. Li, L. Huang, X. Ying, Y. Jian, Y. Hong, F. Hu and Y. Du, Angew. Chemie - Int. Ed., 2015, 54, 3126-3131.

A. Palanisamy and S. A. Sukhishvili, Macromolecules, 2018, 51, 3467-3476.

S. Lin, J. Shang and P. Theato, Polym. Chem., 2017, 8, 2619-2629.

F. Käfer, F. Liu, U. Stahlschmidt, V. Jérôme, R. Freitag, M. Karg and S. Agarwal, Langmuir, 2015, 31, 8940-8946.

W. Fu and B. Zhao, Polym. Chem., 2016, 7, 6980-6991.

G. Chen, B. Ma, Y. Wang, R. Xie, C. Li, K. Dou and S. Gong, ACS Appl. Mater. Interfaces, 2017, 9, 41700-41711.

A. Augé, D. Fortin, X. Tong and Y. Zhao, Polym. Chem., 2018, 9, 4660-4673.

Y. Zhang, Y. Huang and S. Li, AAPS PharmSciTech, 2014, 15, 862-871.

J. Seuring and S. Agarwal, Macromolecules, 2012, 45, 3910-3918.

L. Hou and P. Wu, Soft Matter, 2015, 11, 7059-7065.

B. A. Pineda-Contreras, H. Schmalz and S. Agarwal, Polym. Chem., 2016, 7, 1979-1986.

A. Asadujjaman, B. Kent and A. Bertin, Soft Matter, 2017, 13, 658-669.

A. Asadujjaman, A. Bertin and A. Schönhals, Soft Matter, 2017, 13, 2384-2393.

C. Otsuka, Y. Wakahara, K. Okabe, J. Sakata, M. Okuyama, A. Hayashi, H. Tokuyama and S. Uchiyama, Macromolecules, 2019, 52, 7646-7660.

A. Chapiro and L. Perec-Spritzer, Eur. Polym. J., 1975, 11, 59-69.

C. Hou, L. Ying and C. Wang, J. Mater. Sci., 2005, 40, 609-612.

P. Lertturongchai, M. I. A. Ibrahim, A. Durand, P. Sunintaboon and K. Ferji, Macromol. Rapid Commun., 2020, 4, 2000058.

X. Qiu, F. Tanaka and F. M. Winnik, Macromolecules, 2007, 40, 7069-7071.

L. Sambe, K. Belal, F. Stoffelbach, J. Lyskawa, F. Delattre, M. Bria, F. X. Sauvage, M. Sliwa, V. 
Humblot, B. Charleux, G. Cooke and P. Woisel, Polym. Chem., 2014, 5, 1031-1036.

64 G. Mellot, J.-M. Guigner, L. Bouteiller, F. Stoffelbach and J. Rieger, Angew. Chemie - Int. Ed., 2019, 58, 3173-3177.

65 S. X. Zhou, Z. X. Weng, Z. M. Huang and Z. R. Pan, J. Appl. Polym. Sci., 2001, 79, 1431-1438.

H. Zhang, X. Tong and Y. Zhao, Langmuir, 2014, 30, 11433-11441.

J. N. Israelachvili, D. J. Mitchell and B. W. Ninham, J. Chem. Soc. Faraday Trans. 2 Mol. Chem. Phys., 1976, 72, 1525-1568.

68 A. Blanazs, S. P. Armes and A. J. Ryan, Macromol. Rapid Commun., 2009, 30, 267-277.

69 A. Blanazs, J. Madsen, G. Battaglia, A. J. Ryan and S. P. Armes, J. Am. Chem. Soc., 2011, 133, $16581-16587$.

70 F. Coumes, M. Balarezo, J. Rieger and F. Stoffelbach, Macromol. Rapid Commun., 2020, 41, 2000002.

71 J. Rieger, Macromol. Rapid Commun., 2015, 36, 1458-1471.

72

F. D’Agosto, J. Rieger and M. Lansalot, Angew. Chemie Int. Ed., 2020, 59, 8368-8392.

73 G. Mellot, P. Beaunier, J.-M. M. Guigner, L. Bouteiller, J. Rieger and F. Stoffelbach, Macromol. Rapid Commun., 2019, 40, 1800315.

74 M. J. Derry, L. A. Fielding and S. P. Armes, Prog. Polym. Sci., 2016, 52, 1-18.

75 C. A. Figg, R. N. Carmean, K. C. Bentz, S. Mukherjee, D. A. Savin and B. S. Sumerlin, Macromolecules, 2017, 50, 935-943.

76 D. Le, F. Wagner, M. Takamiya, I.-L. L. Hsiao, G. Gil Alvaradejo, U. Strähle, C. Weiss and G. Delaittre, Chem. Commun., 2019, 55, 3741-3744.

77 L. P. D. Ratcliffe, M. J. Derry, A. Ianiro, R. Tuinier and S. P. Armes, Angew. Chemie - Int. Ed., 2019, 58, 18964-18970.

78 S. M. North and S. P. Armes, Polym. Chem., 2020, 11, 2147-2156.

79 S. J. Byard, C. T. O’Brien, M. J. Derry, M. Williams, O. O. Mykhaylyk, A. Blanazs and S. P. Armes, Chem. Sci., 2020, 11, 396-402.

80 S. Y. Kim, K. E. Lee, S. S. Han and B. Jeong, J. Phys. Chem. B, 2008, 112, 7420-7423.

81 L. A. Fielding, J. A. Lane, M. J. Derry, O. O. Mykhaylyk and S. P. Armes, J. Am. Chem. Soc., 2014, 136, 5790-5798.

82 Y. Pei, L. Thurairajah, O. R. Sugita and A. B. Lowe, Macromolecules, 2015, 48, 236-244.

83 Y. Pei, O. R. Sugita, L. Thurairajah and A. B. Lowe, RSC Adv., 2015, 5, 17636-17646.

84 Y. Pei, N. C. Dharsana, J. A. Van Hensbergen, R. P. Burford, P. J. Roth and A. B. Lowe, Soft Matter, 2014, 10, 5787-5796. 